\title{
Movilizar emociones, cumplir la ley La dimensión performativa de la defensa de los derechos humanos*
}

\author{
Mobilizing emotions, abiding the law \\ The performative dimension of defending of human rights
}

RODRIGO LLANES SALAZAR**

\begin{abstract}
The performative dimension of defending human rights is analyzed as a fundamental element of such practices. The methodology consists of an anthropological literature review regarding human rights and an ethnographical study of an audience concerning indigenous rights before the Inter-American Commission of Human Rights. The main finding was that several performative expressions of the defense of human rights exist: the mob ilizing of emotions, on behalf of the victims; the portrayal of professionalism, on behalf of the defendants; and the demonstration that the law, regardless of economic interests, is abided by the State.
\end{abstract}

Key words: indigenous rights, defendants, State, performance, Inter-American Commission of Human Rights

\section{Resumen}

Se analiza la dimensión performativa de la defensa de los derechos humanos como un elementofundamental de dicha práctica. La metodología consistió en la revisión de la literatura antropológica sobre derechos humanos y el estudio etnográfico de una audiencia sobre derechos indígenas ante la Comisión Interamericana de Derechos Humanos. El principal hallazgofue que existen diversas expresiones performativas de la defensa de los derechos humanos: la movilización de emociones, por parte de las víctimas; la actuación de profesionalismo, por parte de los defensores; y la demostración de que se cumple la ley independientemente de intereses económicos, por parte del Estado.

Palabras clave: derechos indígenas, defensores, Estado, performance, Comisión Interamericana de Derechos Humanos

$\mathrm{U}$ na de las ideas fundamentales de los derechos humanos, tal como es formulada en la Declaración Universal de los Derechos Humanos de la Organización de las Naciones Unidas (onu), a saber, que todos los "miembros de la familia humana" poseen una "dignidad intrínseca", que "todos los seres humanos nacen libres e iguales en dignidad y derechos”, dista de ser evidente. ¿En qué parte del cuerpo humano se ubica esa dignidad inherente, y en dónde radican la libertad e igualdad en dignidad y derechos que todos los seres humanos compartimos al nacer?

\footnotetext{
* Artículo recibido el 05/03/19 y aceptado el 20/05/19.

** Universidad Nacional Autónoma de México, Centro Peninsular en Humanidades y Ciencias Sociales, Exsanatorio Rendón Peniche. Calle 43 s/n entre 44 y 46, col. Industrial, 97150, Mérida, Yucatán, México <rodrigo.llanes@cephcis.unam.mx>. ORCID: http: / / orcid.org/0000-0002-7326-132X.
} 
Como observó la historiadora Lynn Hunt (2009: 18), esa "pretensión de evidencia", la idea de que la dignidad intrínseca de las personas es una verdad "evidente [...] resulta crucial para los derechos humanos", y de ella nace una necesidad de declarar derechos. Pero dichas declaraciones, a pesar de que tuvieron su principal impulso gracias a ideas ilustradas, no son actos únicamente racionales. "Su misma existencia -asevera Hunt (2009: 25)- depende tanto de las emociones como de la razón. La pretensión de evidencia se basa en última instancia en un atractivo emocional; es convincente si toca la fibra sensible de toda persona".

En este artículo abordaré lo que podemos llamar la dimensión performativa de la defensa de los derechos humanos. Hay cinco elementos que me parecen cardinales en el análisis de la dimensión performativa de la vida social: 1) su aspecto "formal", expresivo, estilizado, e incluso "dramático"; 2) su fuerza productiva, es decir, los efectos que produce; por ello, como formuló John Austin, los enunciados performativos deben analizarse en función de las condiciones de felicidad o infelicidad que los hacen eficaces y no en términos de veracidad (en qué medida representan fielmente algo); 3) uno de los efectos particulares que genera: la creación de presencias, esto es, su capacidad de "crear y hacer presentes realidades y experiencias suficientemente vívidas como para conmover, seducir, engañar, ilusionar, encantar, divertir, aterrorizar" (Díaz Cruz, 2008: 40), su capacidad de presentar y representar identidades, tanto las propias como las de los otros, de crear y recrear narrativas; 4) las audiencias frente a las cuales los actores de las performances se presentan y representan; y 5) que las performances no sólo son re-presentaciones, es decir, recreaciones de actos pasados o "conductas restauradas", como les llamó Richard Schechner, sino que también son vehículos que anuncian posibilidades futuras (Austin, 1990; Butler, 2001; Díaz Cruz, 2008, 2014a).

En este sentido, la dimensión performativa de la defensa de los derechos humanos consiste en actos de dramatización que buscan movilizar emociones, tocar fibras sensibles. Sin embargo, la movilización de emociones no es la única expresión de la dimensión performativa de la defensa de los derechos humanos. En este artículo examino también otras manifestaciones: la performatividad del defensor "profesional" de derechos humanos, así como el complejo papel que juega el "Estado" en este fenómeno. Uno de mis argumentos es que la dimensión performativa de la defensa de los derechos humanos tiene como uno de sus efectos la producción del Estado como un otro, el violador por excelencia de los derechos humanos, aunque los actores estatales igualmente llevan a cabo actos performativos relacionados con la protección de tales derechos - por ejemplo, firmar y ratificar tratados internacionales, reformar leyes-como parte de prácticas que crean la idea de "Estado de derecho", es decir, un Estado que cumple la ley y construye legitimidad frente a otros Estados y organismos internacionales.

Para lograr mi objetivo, en la siguiente sección desarrollaré la idea de la dimensión performativa de la defensa de los derechos humanos. Después discutiré al respecto a partir del análisis de una audiencia temática sobre los derechos humanos de los pueblos indígenas efectuada en diciembre de 2016 ante la Comisión Interamericana de Derechos Humanos (CIDH), para ello presentaré elementos del contexto que condujo a la realización de la audiencia y notas etnográficas sobre la misma. Mi análisis se basa en la observación de la audiencia, en la cual participé como parte de la delegación de peticionarios, así como en la investigación que llevo a cabo sobre los derechos del pueblo maya en Yucatán.

\section{Antropología de los derechos humanos: notas sobre su dimensión performativa}

Por lo menos desde la década de los noventa del siglo $\mathrm{xx}$, los estudios antropológicos en torno a los derechos humanos abandonaron los debates entre las posiciones universalistas y relativistas sobre los derechos y se enfocaron en analizar los derechos humanos a partir de las acciones e intenciones de los actores sociales, los usos y significados que le conferían en contextos históricos y relaciones de poder particulares, como resultado de luchas sociales concretas (Wilson, 1997: 3, 23). En este orden de ideas, lo que me interesa examinar es la dimensión performativa de las diversas prácticas socioculturales de defensa de derechos humanos. ${ }^{1}$

Antes de proceder, debo hacer una aclaración importante. Con frecuencia los críticos de los derechos humanos denuncian que la defensa de derechos es un "teatro", un montaje falso en el cual los activistas usan a las víctimas para conseguir recursos (véase

1 Entiendo por defensa de derechos humanos un amplio conjunto de prácticas: la elaboración de declaraciones y pronunciamientos, la impartición de charlas y talleres de "concientización” y "sensibilización", la visita a presos políticos, la organización de seminarios y workshops, la celebración de audiencias, la realización de marchas o la defensa legal. 
Allen, 2013: 58), mas cuando abordo la dimensión performativa de la defensa de derechos como actos de dramatización no me refiero a actuaciones en un sentido de "farsa", sino que aludo a que todo rol social implica cierta ritualización, una presentación del yo en el curso de la vida social (Goffman, 1981). Y, reiterando una de las notas constitutivas del análisis performativo, mi interés no radica en evaluar en qué medida una representación se apega al referente, sino los efectos que produce gracias a la manera en que es presentada ante una determinada audiencia.

Una de las principales preocupaciones en los estudios antropológicos relativos a los derechos humanos es la forma en que las ideas globales sobre derechos, tales como han sido expresadas en documentos como la Declaración Universal, los dos pactos internacionales (sobre derechos civiles y políticos, así como sobre derechos económicos, sociales y culturales) y diversas convenciones, han sido apropiadas y movilizadas por actores sociales en diferentes contextos. En este aspecto, el trabajo de Sally Merry (2006) sobre la vernacularización de los derechos humanos ha sido de gran influencia. De acuerdo con Merry (2006: 136), un elemento fundamental del proceso de vernacularización de las ideas globales del derecho internacional de derechos humanos a contextos locales es el marco (frame): aquellas imágenes, símbolos e historias a través de los cuales las ideas son presentadas en narrativas y concepciones culturales locales y específicas.

Según ha observado Rodrigo Díaz Cruz (2008: 43), el marco (frame) también es un componente clave de la performance: "toda performance supone, por tanto, comportamientos 'enmarcados' que constituyen, que crean, eventos sociales contextualizados que exaltan e intensifican la experiencia social". Así, la defensa de los derechos humanos enmarca hechos particulares como "violaciones de derechos humanos"; al hacerlo, también suele construir identidades como la de la víctima, cuyos derechos fueron violados, o la del enemigo, el perpetrador de las violaciones (comúnmente el Estado). De este modo, la defensa transforma narrativas: el golpe que una mujer recibe de su esposo puede dejar de ser visto como "la cruz que debe cargar", para reformularse en un acto de violencia de género; asimismo, las prácticas de corrupción y engaño cometidas en una asamblea ejidal se transforman en violaciones al derecho a las tierras y territorios.

En el proceso anterior, la forma en que se presentan los actores es crucial. Diana Taylor (1997) ha analizado la performance de las Madres de la Plaza de Mayo, quienes, con sus pañuelos blancos que las identifican como grupoy, sobre todo, con la exposición de las fotos de sus hijos desaparecidos y pancartas con consignas como "Aparición con vida", visibilizan su sufrimiento y desafían el discurso hegemónico sobre las madres y las mujeres en cuanto sujetos no políticos, confinadas al espacio doméstico.

En este sentido, la dimensión afectiva de la vida sociocultural es una parte esencial en la defensa de los derechos humanos que no siempre ha sido advertida. $\mathrm{Al}$ respecto, podemos retomar la propuesta de análisis de Edith Calderón Rivera (2012) sobre cuatro aspectos de dicha dimensión: en el ámbito individual, los aspectos constitutivos y transmisivos, y en el ámbito social, los aspectos descriptivos y expresivos de las emociones, pasiones, sentimientos y afectos. En este orden de ideas, las performances son medios clave para la expresión y movilización estratégica de emociones de un individuo o un colectivo; una forma de dramatizar y exhaltar los aspectos descriptivos y expresivos de las emociones. Si las performances son eficaces pueden tener efectos en la constitución de emociones de sus audiencias.

\section{Performar el profesionalismo}

Sin embargo, la dimensión performativa de la defensa de los derechos humanos no se reduce a la construcción de la identidad de la víctima y a la narrativa que configura para movilizar afectos de su audiencia. El proceso de "profesionalización" o "institucionalización" de las organizaciones de derechos humanos ha estado acompañado de la construcción de nuevas identidades por parte de los defensores y, en consecuencia, de nuevas formas de presentarse a sí mismos y frente a otros. En su estudio sobre activistas de derechos humanos en Colombia, Winifred Tate (2007) argumenta que, en la década de los noventa, la profesionalización de las organizaciones de derechos humanos privilegió un nuevo modelo de producción de conocimiento sobre derechos humanos, "basado en estándares legales y enfocado en la credibilidad, en la elaboración de reclamos cuantificables y verificables" (2007: 118).

Podemos destacar dos procesos que han acompañado a la identidad del activista profesional de derechos humanos: por un lado, la creciente judicialización de la política, esto es, que cada vez más los reclamos $\mathrm{y}$ movilizaciones sociales se formulan en amparos y pasan por tribunales, lo cual ha devenido incluso en un "fetichismo de la ley" (Comaroff y Comaroff, 2009), con un creciente peso del derecho internacional de derechos humanos (Simmons, 2009). Por otro lado, el papel cada vez más importante que juegan los indicadores cuantitativos como la manera de leer, conocer y representar al mundo. De acuerdo con Sally 
Merry (2011), los indicadores, en especial aquellos que se basan en números o medidas, proveen un aura de verdad objetiva y facilitan comparaciones. No obstante, al convertir un problema en una serie de medidas, también se suele pasar por alto los detalles particulares de contexto e historia. La creciente relevancia de los indicadores se debe, argumenta Merry, a la hegemonía del modelo de gobernanza promovida por las corporaciones y organismos internacionales como el Banco Mundial, el cual está cada vez más presente en campos como el de los derechos humanos y la ayuda humanitaria. En pocas palabras, los profesionales de derechos humanos deben presentarse frente a ciertas audiencias como conocedores del derecho, particularmente del internacional (y sus "estándares internacionales"), expresando sus denuncias con base en indicadores, estudios fundamentados en cifras que proyecten un aura de verdad objetiva, creíble. "Ser profesional -escribe Tate (2007: 205)- requiere objetividad, familiaridad con el derecho internacional y elaborar reportes bien documentados".

Desde luego, los efectos de la dimensión performativa de los derechos humanos suelen ser múltiples y hasta contradictorios. La dramatización de la condición de víctima puede efectivamente movilizar emociones, tocar fibras sensibles, ganar simpatías; la performance profesional, que moviliza el derecho internacional y presenta datos confiables, puede ganar un caso legal. Pero también existen riesgos. Uno es que la dramatización de la condición de víctimas se convierta en una romantización y exotización que reproduzca y fortalezca estereotipos y relaciones de poder, que congele a las víctimas en un estado de indefensión, que inhiba su capacidad de agencia. Por otra parte, la fuerte presencia del derecho internacional y de los indicadores corre el peligro de convertir el trabajo de
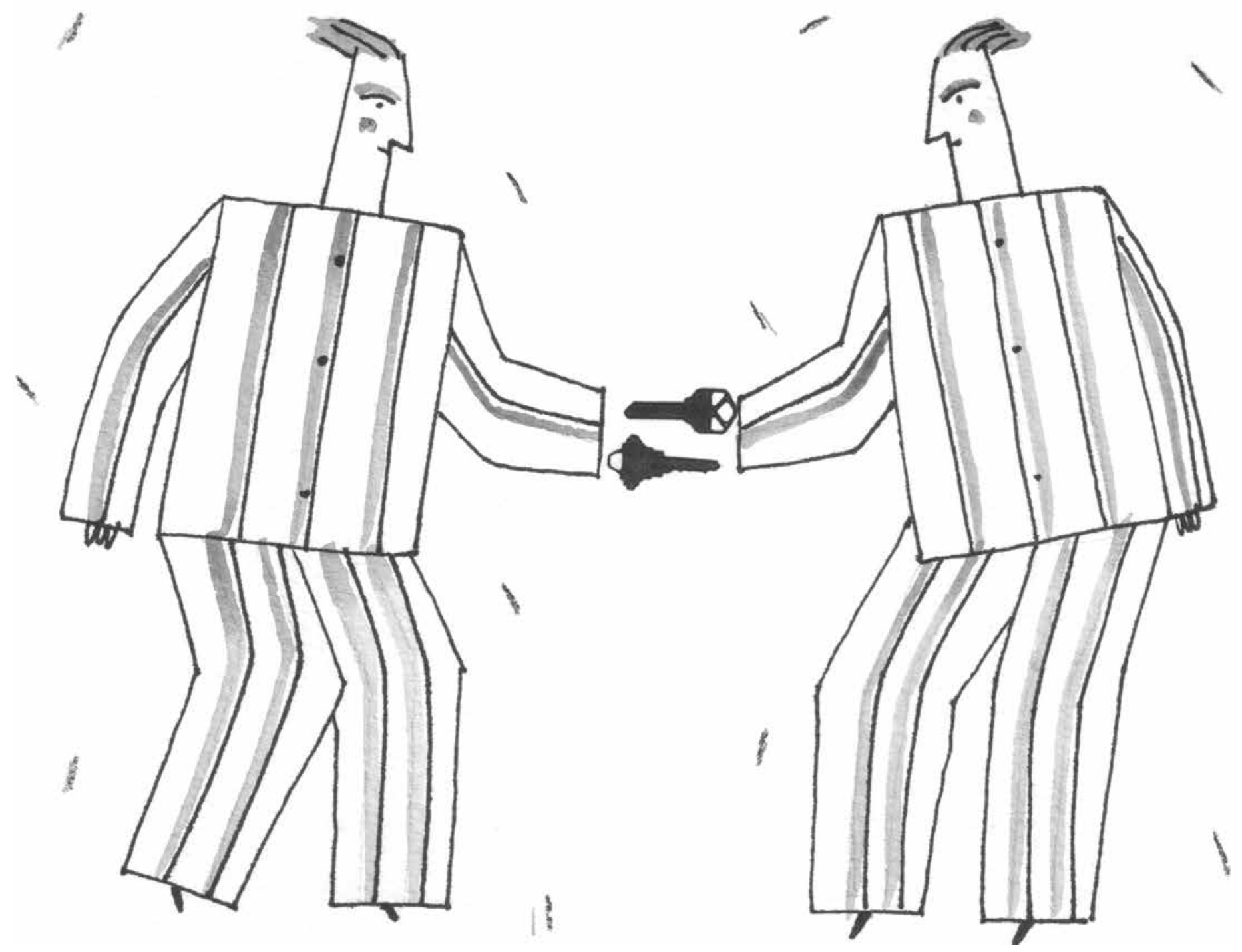
defensa en un asunto únicamente de abogados y expertos técnicos, lo cual puede excluir a otros actores en los procesos de defensa (Kennedy, 2002).

\section{La cuestión del Estado}

Lo anterior nos lleva a la cuestión del Estado. A pesar de que organismos como la onu han enunciado ya disposiciones sobre el papel de las empresas en la protección de los derechos humanos, en las formulaciones clásicas sobre el tema el Estado es el principal y en ocasiones el único actor que por definición viola derechos humanos. Para abordar mejor el problema, es esencial no fetichizar al Estado como una entidad homogénea, sino analizarlo a partir de las prácticas cotidianas que lo construyen discursivamente (Gupta, 1995); de los ejercicios de legitimación de la idea del Estado que enmarcan prácticas políticas que necesitan ser legitimadas (Abrams, 1988); y de los procesos que tienen como efecto la producción de la idea del Estado en cuanto un ámbito separado de la sociedad y de la economía (Mitchell, 1990).

Así, en primer lugar, debemos considerar que la dimensión performativa de los derechos humanos no sólo dramatiza las identidades de la víctima y de los defensores, sino que además construye al Estado como un actor dotado de agencia, como el "salvaje" perpetrador de violencia (Mutua, 2001). En este sentido, la defensa de derechos humanos produce un "efecto de Estado" (Mitchell, 1990), separando claramente a dicha entidad de los ciudadanos.

No obstante, las caracterizaciones del Estado neoliberal, entendido como uno que reduce su faceta de bienestar, que aumenta su cara punitiva (Wacquant, 2010) y cuyo compromiso principal es promover y atraer inversiones privadas para generar crecimiento económico, para lo cual debe brindar certeza jurídica a los inversionistas, complican la idea anterior. Partiendo de estas consideraciones teóricas, no es que en tiempos preneoliberales existiera una separación más patente entre el Estado, por un lado, y la economía o el mercado, por el otro, sino que las prácticas que producen los efectos de esa separación han cambiado. Veamos algunas de estas prácticas en el campo de los derechos humanos.

El desarrollo de actividades extractivas y otros proyectos de inversión, por lo general impulsados por los gobiernos, son comúnmente enmarcados por sus promotores como fuentes de crecimiento económico y de empleo, mientras que activistas de derechos humanos suelen denunciarlos como megaproyectos que despojan territorios y violan derechos; incluso, es usual que los activistas delaten la "captura corporativa del Estado", como si éste fuese una entidad claramente delimitada que, como pez en el mar, es atrapada por un poderoso pescador corporativo con su red. Para el desarrollo de tales proyectos, los actores estatales han recurrido a varias estrategias, desde prácticas clientelares hasta violencia y represión (Sierra, Hernández y Sieder, 2013), pero también a actos performativos para legitimar la idea del Estado de derecho (Nader y Mattei, 2013): un Estado que "cumple la ley” y protege los derechos humanos de sus ciudadanos, que está por completo separado del poder económico. Parafraseando a Abrams (1988), si se pudiera ver tal como es la relación entre actores estatales que promueven y se benefician de proyectos de inversion privada, con facilidad la situación sería considerada ilegítima, una dominación inaceptable: por ello es necesaria la construcción del Estado en cuanto entidad separada de los intereses económicos y que cumple la ley. En esto juega un papel decisivo la dimensión performativa de los derechos humanos.

La antropología política y simbólica ha estudiado cómo el poder necesita de símbolos, imágenes, rituales, ceremonias, dramatizaciones y teatralidad para ser ejercido (Díaz Cruz, 2014b). Un asunto central para la construcción de legitimidad del Estado contemporáneo es la protección de los derechos humanos. "Ya no es aceptable para un gobierno hacer reivindicaciones de soberanía en defensa de abusos graves de derechos humanos", ha escrito Beth Simmons (2009: 3). Para ello, la firma y ratificación de tratados internacionales de derechos humanos resulta crucial. Además de los objetivos instrumentales explícitos de la firma y ratificación de los tratados internacionales -modificar las prácticas de protección de derechos humanos, las cuales muchas veces no se cumplen-, éstos también poseen una dimensión expresiva: declaran o expresan a la comunidad internacional la posición de los países que los han firmado y ratificado; esperan ser recompensados más por sus compromisos internacionales que por su conducta interna (Hathaway, 2002). En su análisis sobre el campo de los derechos humanos en Palestina, Lori Allen (2013) ha documentado que, para diversos actores, los derechos humanos son una performance para enviar un mensaje a la comunidad internacional, para obtener legitimidad y financiamiento externo. Así, afirma Allen (2013: 142), los derechos humanos se han convertido en parte sustancial de la concepción de la legitimidad del Estado.

En este orden de ideas, los actos performativos de protección de derechos humanos que los gobiernos suelen realizar, además de la firma y ratificación de tratados internacionales (Merry, 2006: 79), son las 
prácticas "ritualistas" por medio de las cuales expresan su compromiso con los medios institucionales de protección de derechos humanos (Adcock, 2012); esto significa, en muchos casos, un énfasis en los cambios legales -reformas y leyes, sobre todo de derechos considerados "permitidos" (Hale, 2002), aquellos que no subvierten las bases de la economía política capitalista- y en los procedimientos burocráticos (véase Perreault, 2015). Por ello, es común que cuando los gobiernos tienen que rendir cuentas sobre avances en el cumplimiento de tratados internacionales o en audiencias en materia de derechos indígenas, exhalten los cambios legales e institucionales que han llevado a cabo, añadiendo que aún hay "brechas de implementación” que deben ser atendidas.

\section{Cambiar la narrativa: de la tranquilidad y el crecimiento a las violaciones de derechos indígenas}

A inicios de diciembre de 2016 se celebró la audiencia temática "La situación de los derechos humanos de los pueblos indígenas en Yucatán" ante la cIDH en la ciudad de Panamá. Los principales asuntos abordados en la audiencia fueron los impactos de la siembra de soya genéticamente modificada (gm) en la deforestación, afectación a la apicultura y contaminación del agua por el uso de plaguicidas y las violaciones al derecho a la consulta previa, libre e informada sobre la siembra de dicho monocultivo en Campeche. También se trataron, en menor medida, algunos problemas relacionados con el desarrollo de proyectos de energías renovables en Yucatán. Para entender lo sucedido en la audiencia a la luz de las ideas sobre la dimensión performativa de la defensa de los derechos, es preciso ofrecer algunas notas de contexto.

En 2012, la Secretaría de Medio Ambiente y Recur sos Naturales (Semarnat) dio un permiso a Monsanto para la siembra comercial de soya gm en 253000 hectáreas distribuidas en los estados de Campeche, Yucatán, Quintana Roo, Chiapas, Veracruz, San Luis Potosí y Tamaulipas, aunque su siembra se ha estado realizando en Campeche, en fases piloto y experimental, desde el año 2000. Por su parte, en 2016, el Centro Nacional de Control de Energía dio a conocer el fallo de una subasta de energía eléctrica a largo plazo en la que nueve proyectos de energía renovable serían desarrollados por empresas privadas en Yucatán, incluyendo un parque fotovoltaico de más de un millón de paneles solares promovido por la empresa Vega Solar.

Para los gobiernos estatales, federal y sus promotores, los proyectos de siembra de soya gm y de parques de energía renovable son importantes contribuciones para el crecimiento económico y la generación de empleos en dichos estados y se justifican bajo principios humanitarios y ecológicos: la producción de cultivos gm como la soya ayudaría a alimentar a la población pobre del mundo, y el desarrollo de parques de energía eólica y fotovoltaica conllevaría la reducción de emisiones de dióxido de carbono.

Sin embargo, la narrativa de crecimiento económico, creación de empleos e impacto ecológico positivo ha sido contestada por distintos actores. Tanto la siembra de soya gm como los parques eólicos y solares están destinados a ser desarrollados parcialmente en tierras ejidales y en zonas habitadas por comunidades indígenas, por ende, organizaciones y activistas de derechos indígenas se han involucrado en estos casos.

No obstante el elevado porcentaje de población indígena en Campeche ( $22 \%$ de la población) y Yucatán (65\%), el problema de los derechos de los pueblos indígenas en la península de Yucatán no ha sido un asunto presente en los informes sobre la situación de derechos humanos por parte de organismos locales, nacionales e internacionales, ni de estudio en la academia, como sí lo ha sido el tema de los derechos de los mayas de Chiapas y Guatemala, quienes han sufrido diversas formas de represión y violencia, desde desplazamientos forzados hasta violencia sexual y genocidio (Kovic, 2005; Pitarch, Speed y Leyva, 2008; Speed, 2008).

A pesar de que Campeche y Yucatán son dos de los estados más "seguros" de México debido a su baja tasa de homicidios, la falta de visibilización del asunto de los derechos de los pueblos indígenas en la región no se debe a que los mayas y otros indígenas de esas entidades se encuentren libres de violaciones de sus derechos humanos, sino que, a diferencia de Chiapas y Guatemala, no ha habido una fuerte presencia de la Iglesia progresista ni una amplia red de organizaciones de la sociedad civil dedicadas a la defensa de los derechos humanos (Llanes Salazar, 2019). Una de las notables excepciones es Equipo Indignación, organización creada en 1990 en Yucatán, que tuvo sus orígenes en las comunidades eclesiales de base y en la defensa de derechos civiles y políticos, pero que, tras el levantamiento del Ejército Zapatista de Liberación Nacional y su trabajo en el caso de un indígena maya preso sin traductor intérprete, se ha enfocado en la defensa de los derechos del pueblo maya, en particular a su libre determinación y a su territorio-derechos que expresan bajo las consignas "En el pueblo manda el pueblo" y "Los montes también son nuestros".

Equipo Indignación es precisamente la organización local que ha acompañado la defensa legal de 
comunidades mayas en contra de la siembra de soya gm, aunque también han participado otras organizaciones de derechos humanos y ambientalistas de México. En el proceso de defensa, las organizaciones han construido otra narrativa, en la que la siembra de soya gm no se considera una promesa de crecimiento económico, de productividad en el campo ni de generación de empleos, sino más bien una amenaza de deforestación de la "selva maya", de contaminación del agua por el uso de plaguicidas y de violaciones de los derechos del pueblo maya a su libre determinación, a su territorio y a ser consultados previamente. En respuesta a varios recursos legales interpuestos por las organizaciones, a fines de 2015, la Suprema Corte de Justicia de la Nación suspendió el permiso de siembra de soya gm hasta consultar a las comunidades afectadas. Ese mismo año, la Comisión Nacional de los Derechos Humanos ( $\mathrm{CNDH}$ ) había emitido una recomendación que también disponía realizar una consulta, la cual inició en abril de 2016 y, como ordenó la Suprema Corte, las autoridades responsables han sido la Comisión Intersecretarial de Bioseguridad de los Organismos Genéticamente Modificados (Cibiogem) y la Comisión Nacional para el Desarrollo de los Pueblos Indígenas (CDI).

En el proceso de consulta se aprecian algunas de las prácticas cotidianas que construyen el efecto del Estado. Desde la perspectiva de diversos participantes indígenas y defensores en el proceso de consulta, en estas prácticas cotidianas se han podido encontrar cara a cara con el gobierno federal y han podido apreciar cómo la Cibiogem está a favor de la empresa Monsanto y de la siembra de soya gm: no sólo el gobierno federal subsidia la siembra de soya (y, en cambio, ya no lo hace con el maíz), sino que la información que proporciona el Estado es a todas luces favorable a la soya gm, pese a que varias dependencias de la Semarnat recomendaron no otorgar el permiso de siembra comercial por sus posibles impactos ambientales negativos. Asimismo, las empresas agroindustriales cuentan con una importante participación en los consejos consultivos, técnicos y científicos del gobierno federal (Beristain Navarro, 2014). Las violaciones al derecho a la consulta cometidas en este proceso han sido documentadas por una misión de observación civil (Llanes Salazar y Torres-Mazuera, 2017).

El proceso anterior es el contexto en el cual se llevó a cabo la audiencia ante la ciDH, pero ésta debe entenderse ante todo como producto de un proyecto de promoción de defensa de derechos humanos de los pueblos indígenas en la península de Yucatán, por medio del fortalecimiento del liderazgo de organizaciones no gubernamentales, dirigido por la Fundación para el Debido Proceso (DPLF, por sus siglas en inglés). Con sede en Washington, la DPLF es un organismo que promueve el Estado de derecho y entre sus actividades se encuentra el uso de los recursos del Sistema Interamericano (como las audiencias temáticas) para visibilizar temas urgentes de derechos humanos en América. El proyecto de la DPLF tiene como "aliadas" a tres organizaciones de la península de Yucatán: Equipo Indignación; Diálogo y Movimiento A. C., con sede en Campeche, la cual se ha ocupado en la excarcelación de población indígena; y el Consejo Regional Indígena y Popular de Xpujil (CRIPX), que ha trabajado en la región de Calakmul (Campeche) y se ha involucrado en uno de los casos de parques de energías renovables en Yucatán. Fueron estos organismos, junto con la misión de observación de la consulta sobre la siembra de soya gm, los que solicitaron la audiencia temática ante la cIDH.

\section{La audiencia ante la CIDH}

La audiencia temática "La situación de los derechos humanos de los pueblos indígenas en Yucatán" se llevó a cabo el 6 de diciembre de 2016 en un elegante hotel de cuatro estrellas en la ciudad de Panamá. Al igual que otros eventos internacionales de derechos humanos, el ambiente del periodo de sesiones era cosmopolita: en el lobby y en los pasillos del hotel, integrantes de organizaciones de derechos humanos $\mathrm{y}$ fundaciones se saludaban e intercambiaban materiales, por ejemplo, informes (Merry, 2006).

Como anuncié al inicio de este trabajo, formé parte de la delegación de peticionarios de dicha audiencia, la cual estuvo conformada por un consultor de la DPLF; un abogado de Equipo Indignación; una integrante de Diálogo y Movimiento; el líder y un miembro del CRIPX; la abogada de una organización de derecho ambiental; un apicultor y campesino maya de Campeche, afectado por la siembra de soya gm; y un ejidatario de San José Tipceh, donde se desarrollaría el parque fotovoltaico Ticul. El consultor de la DPLF, con una amplia experiencia en la petición y realización de audiencias ante la ciDH, coordinó la preparación de ésta, en particular la distribución de los temas y la organización del tiempo. Como cada una de las partes de la audiencia -la delegación de peticionarios y la del Estado- dispone sólo de 20 minutos para presentar sus argumentos, tuvimos que ensayar nuestras intervenciones para cumplir puntualmente con el tiempo.

Las audiencias temáticas forman parte de las funciones "políticas" de la ciDH con el propósito de estimular la conciencia de los derechos humanos en América. Por 
Foto 1. Deforestación

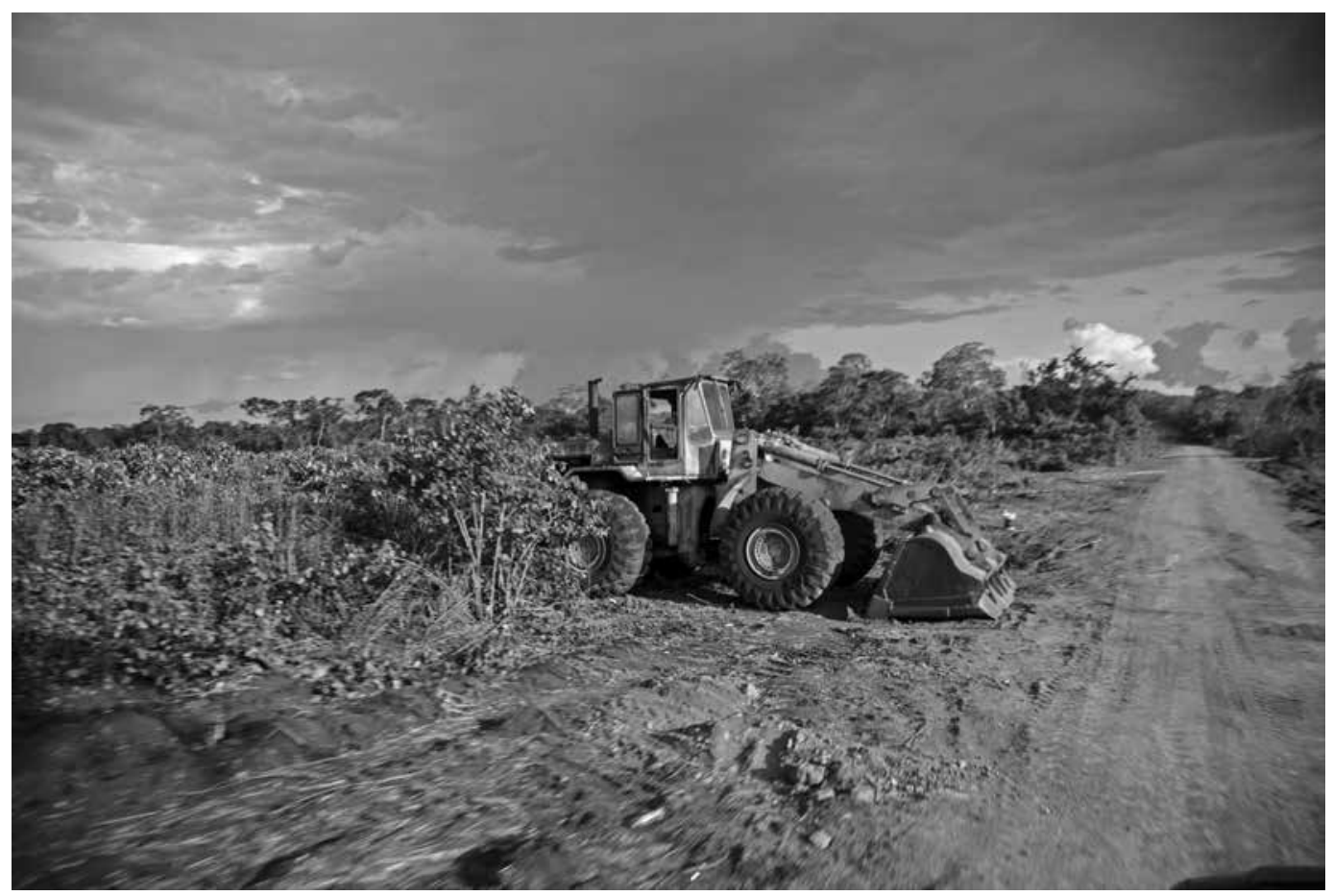

Foto: Robin Canul.

parte de los peticionarios, uno de los objetivos clave era, además de informar a la cIDH sobre la situación de los derechos humanos de los pueblos indígenas de Campeche y Yucatán y visibilizar esta problemática, articular una narrativa: que la península de Yucatán no es sólo Cancún (Lovatón, 2017). O sea, que esta región no es únicamente el paraíso caribeño turístico, sino que en ella también se viven "graves violaciones a los derechos humanos de los pueblos indígenas" relacionados con la contaminación del agua, la deforestación, la muerte de las abejas y la falta de respeto del derecho a la consulta previa (Lovatón, 2017: 58).

En la preparación del informe para la audiencia, los peticionarios contábamos con una gran cantidad de información en torno al asunto de la soya gm y el proceso de consulta sobre el tema. Pero la cuestión de los parques de energía renovable resultaba más problemática, en parte porque había poca información al respecto, debido a que la subasta del parque se había realizado en marzo de 2016, unos meses antes de la audiencia. Además, una cosa es denunciar a Monsanto y los transgénicos, los cuales han sido objeto de polémica en diversos países, y otra muy distinta pronunciarse en contra de los parques de energía renovable, que suelen ser promocionados como generadores de energía "limpia” y "sustentable”. Entonces, el objeto de crítica no era la energía renovable en sí, sino la forma en la que se estaban desarrollando los parques en Yucatán, en especial el caso del parque fotovoltaico Ticul A y Ticul B, sobre el cual unos ejidatarios habían denunciado la existencia de engaños en el contrato de arrendamiento de sus tierras y que no se había efectuado una consulta previa.

La audiencia comenzó a las 11 de la mañana. En un ambiente formal, el comisionado peruano Francisco Eguiguren dio la bienvenida, presentó a los otros dos comisionados y otorgó la palabra a la delegación de peticionarios. El consultor de la DPLF, vestido de traje y corbata, agradeció a la CIDH haber "abierto este espacio para poder mostrar a la Comisión y también a la opinión pública nacional e internacional los serios problemas de violaciones de los derechos humanos de los pueblos indígenas de la península de Yucatán que suelen ser invisibilizados en relación a otros problemas serios que también sufre el Estado [mexicano]". Enseguida fue la intervención de José,$^{2}$ un apicultor y campesino maya de Campeche. Vestido con una guayabera de manga corta, se presentó en lengua maya yucateca ante los tres comisionados de la ciDH, la delegación del Estado mexicano y los demás asistentes de la audiencia: "Mi nombre es José, vengo de la comunidad de San Francisco Suctuc del municipio de Hopelchén,

\footnotetext{
2 El nombre ha sido cambiado.
} 
Foto 2. Contaminación del agua

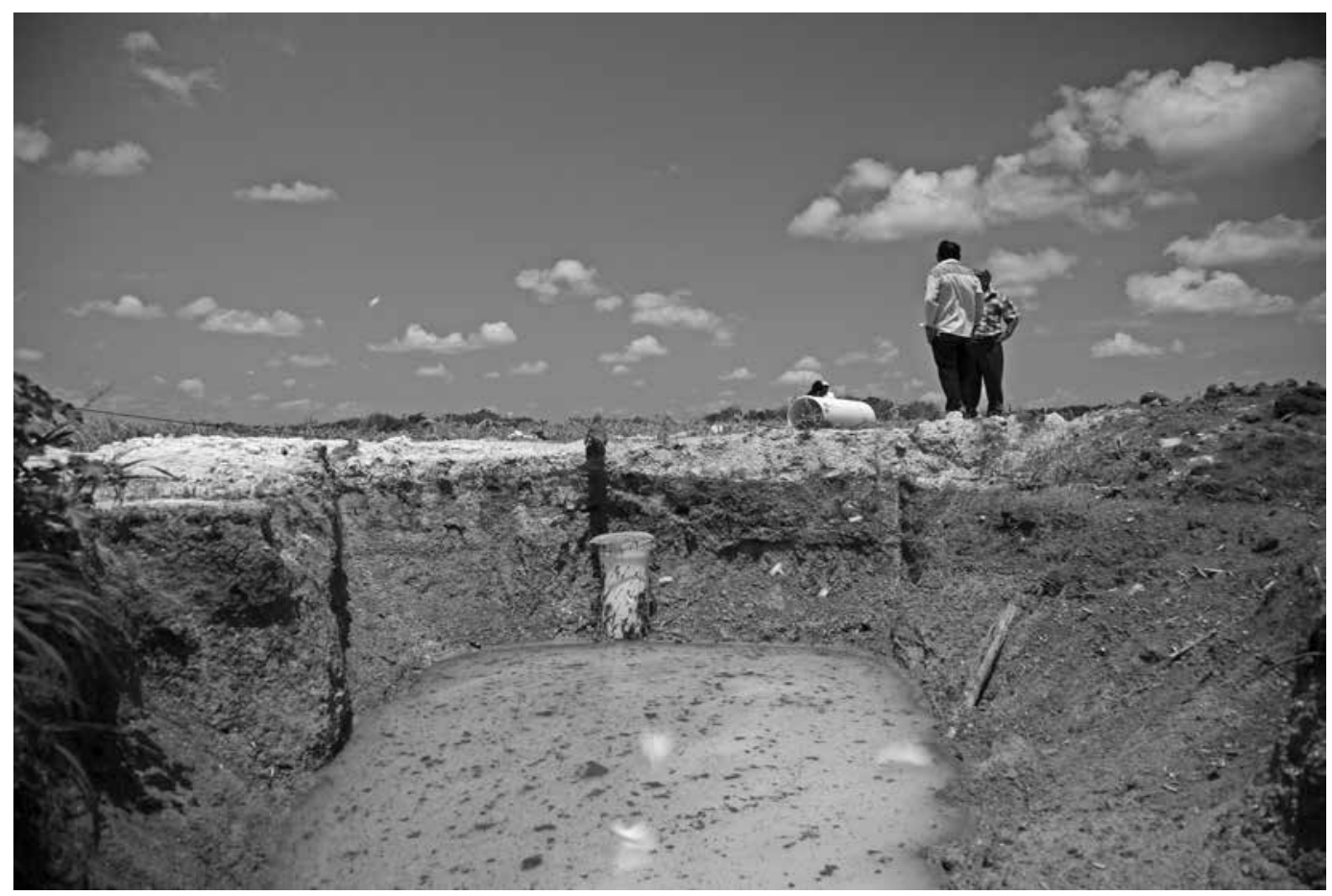

Foto: Robin Canul.

estado de Campeche, tierras mexicanas. Desde mi corazón maya: tengan muy buenos días”. De inmediato señaló que su "familia es semejante a todas las familias de la península de Yucatán", se denominó a sí mismo como apicultor -"somos apicultores por herencia"- y mencionó con orgullo una empresa campesina productora y exportadora de miel a Alemania y Suiza de la cual formaba parte -"muy orgullosos de ser campesinos y hacer esta actividad".

No obstante, expuso José, en los últimos 15 años su trabajo ha entrado en crisis:

Vemos con mucha tristeza la baja de producción de nuestras milpas [...] vemos con tristeza la destrucción de nuestro futuro. La causa de este daño [es la] gran deforestación que existe en la región, la desaparición de la selva maya. Junto a esto aparecen los monocultivos, las avionetas y las fumigaciones de toneladas de veneno que matan a la abeja.

Además de presentarse a sí mismo frente a la audiencia, las palabras de José articulaban una narrativa: los apicultores y los campesinos mayas de Hopelchén han vivido bien gracias a la producción y comercialización de la miel y a sus milpas, pero la deforestación asociada con los monocultivos y el incremento del uso de plaguicidas están destruyendo ese modo de vida y ese futuro. Estos hechos constituyen la emoción de tristeza en José, la cual, señala, es compartida por su comunidad. Su presentación expresa y moviliza la tristeza ante una audiencia por medio de palabras, así como de imágenes de selva deforestada, devastada; de pozos de absorción y de envases de plaguicidas vacíos junto a otros plásticos y latas en un montón de basura, proyectadas en el salón. Si bien José no mencionó las palabras "derechos humanos", "pueblos indígenas" o "industrias extractivas", la suya es una narrativa bien conocida por parte de su audiencia en la CIDH, la cual publicó en 2015 el informe Pueblos indígenas, comunidades afrodescendientes y recursos naturales: protección de derechos humanos en el contexto de actividades de extracción, explotación y desarrollo, entre las cuales se encuentra la siembra del monocultivo de soya transgénica. Así, la identidad indígena de José y la expresión de tristeza por el impacto de las actividades de desarrollo en su comunidad constituyeron condiciones adecuadas para la eficacia de sus intervenciones.

Después participó el abogado de Equipo Indignación. Portando un saco, dio los buenos días a los comisionados y se centró en el problema de la contaminación del agua. En su intervención expuso datos sobre el tema, afirmando que el "acceso a este derecho [al agua] está en riesgo por la contaminación” debido a la política de monocultivos y uso de agrotóxicos. Citó tres ejemplos de estudios que "demuestran lo 


\section{Foto 3. Avioneta con plaguicidas}

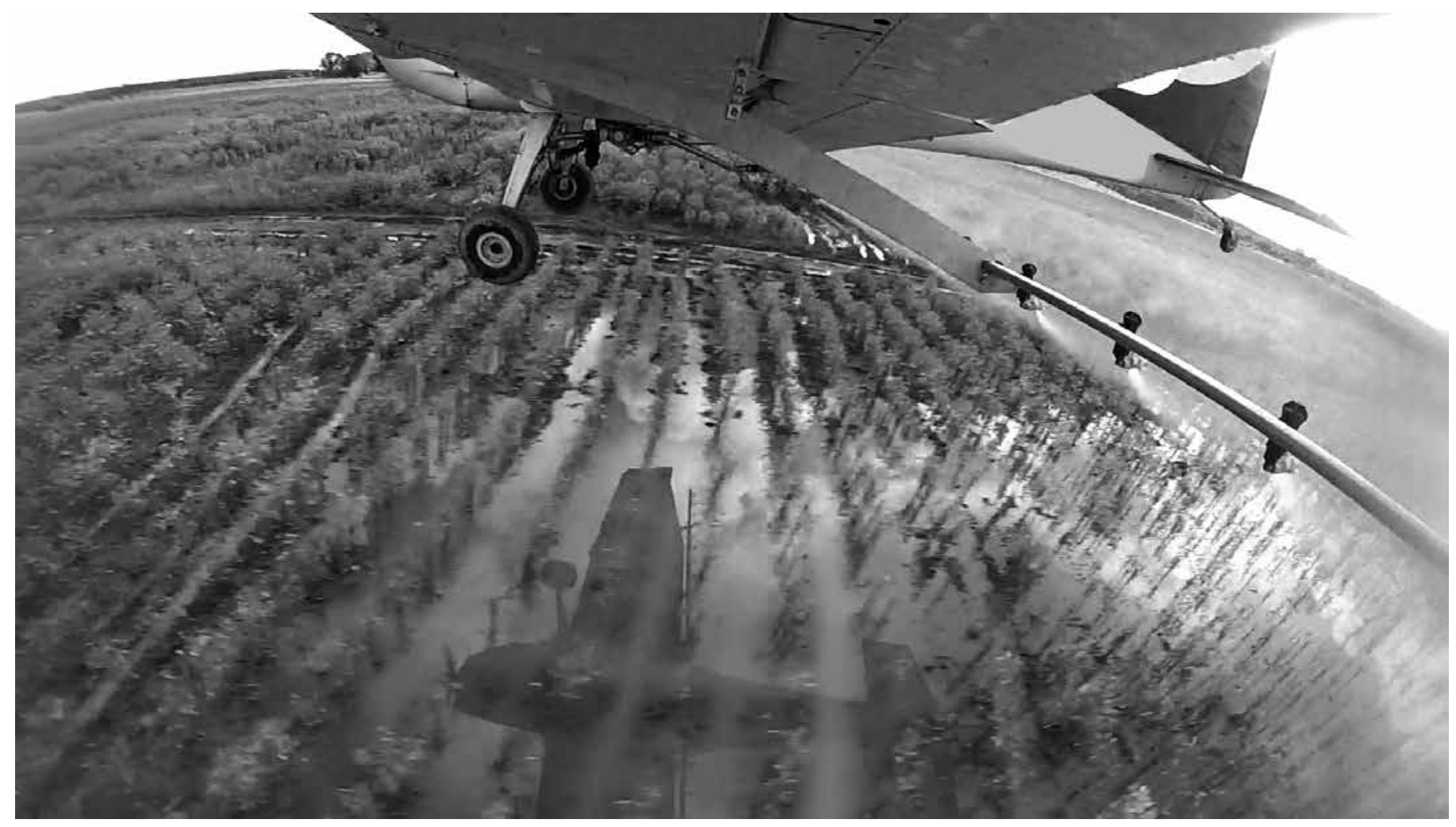

Foto: Robin Canul.

anterior": uno sobre la contaminación de cenotes por plaguicidas organoclorados y sus efectos en el cáncer cervicouterino y mamario; otro en torno a la contaminación de cuerpos de agua superficial por el herbicida glifosato en Hopelchén, que exhiben índices mayores a los permitidos por la Organización Mundial de la Salud; y un informe sobre la presencia de Endosulfán -un plaguicida altamente tóxico y prohibido en diversos países del mundo- en costas y lagunas de la península. "A pesar de estas evidencias -denunció el abogado- el Estado mexicano sigue implementando políticas de monocultivos [...] el agua de la península se está envenenando".

En gran medida, la intervención del abogado de Equipo Indignación puede entenderse desde lo antes expuesto sobre la identidad profesional del defensor de derechos humanos: un actor que debe demostrar conocimiento del derecho, sobre todo del internacional, y que debe presentar información confiable, sobre todo con indicadores cuantitativos. Pero además hay que agregar que este abogado comparte una visión crítica del derecho. En conversaciones con él previas y posteriores a la audiencia, ha expresado un compromiso con el "uso contrahegemónico" del derecho; en sus discursos públicos es severamente crítico con el Estado -como lo es Indignación, organización de la que forma parte-, y también lo es de la sobrevaloración del derecho internacional: para él, la incidencia política ante organismos internacionales no debe significar el abandono del trabajo directo con las víctimas en comunidades locales.

Es difícil apreciar los elementos anteriores en la intervención del abogado en la audiencia, lo cual, insisto, no quiere decir que haya fingido una posición, sino que la situación requiere cierto tipo de presentación. Pese a ello, es posible advertir su postura política cuando los datos acerca de la contaminación del agua en Yucatán fueron enmarcados en términos del derecho humano al agua, y, sobre todo, del papel del Estado-"sigue implementando políticas de monocultivos"-, al cual denuncia con la dramática frase: "el agua de la península se está envenenando".

No me detendré en las demás intervenciones de la delegación de peticionarios, sino en la respuesta de los integrantes de la delegación del Estado. El primero en tomar la palabra fue el subsecretario de Relaciones Exteriores, un funcionario con amplia experiencia diplomática, quien presentó formalmente a la delegación. Después intervino la secretaria ejecutiva de la Cibiogem, que es la responsable de la consulta sobre 


\section{Foto 4. Envases de plaguicidas}

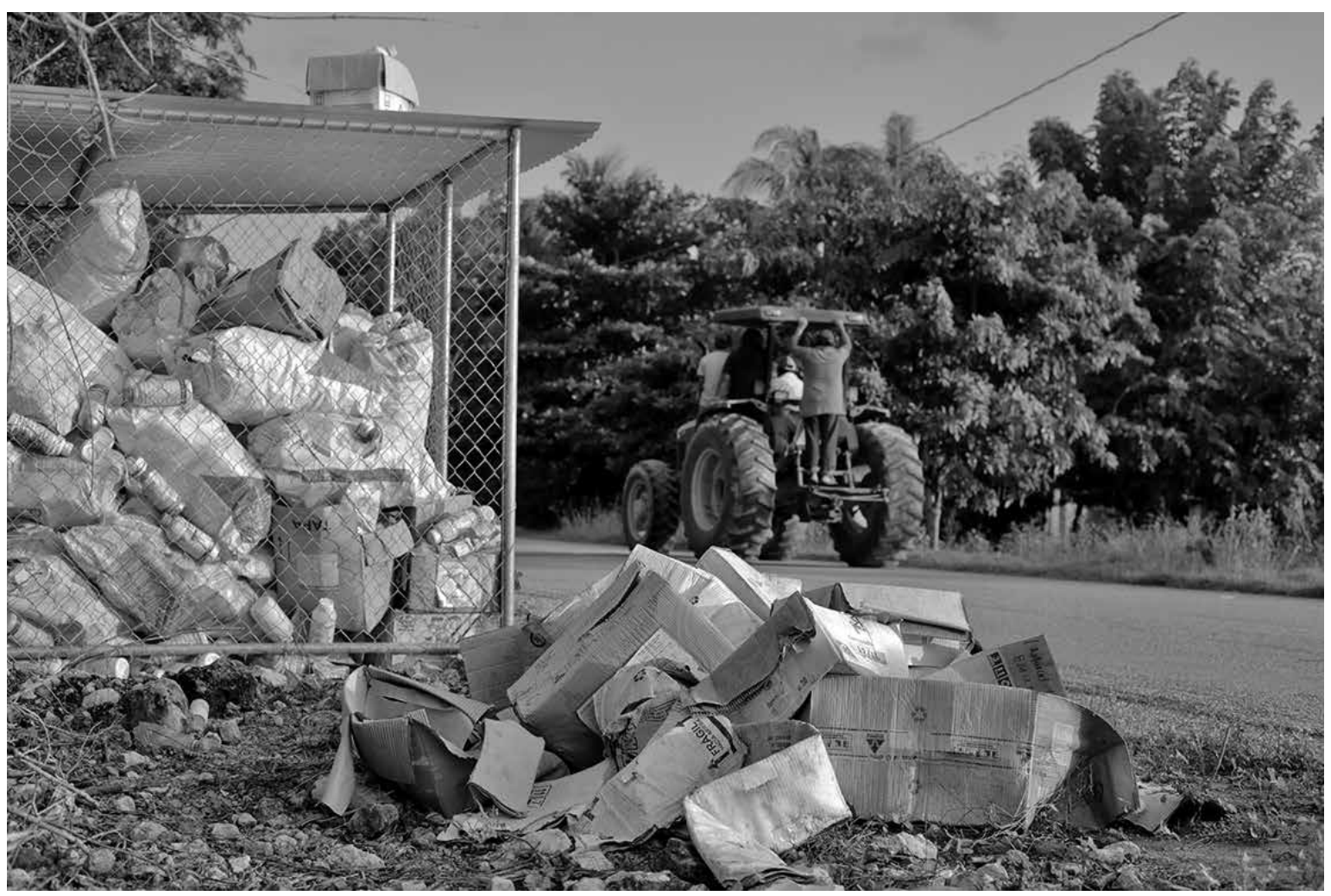

Foto: Robin Canul.

la soya gm en Campeche. Vestida también con saco, presentó su nombre en lengua maya, acto que ha ejecutado en algunas sesiones de consulta en Campeche, tal vez ante las críticas de que la consulta no ha sido "culturalmente adecuada". Su exposición se centró en el "sistema normativo" de México "que regula el uso de los organismos genéticamente modificados". México, señaló, cuenta con las "autoridades e infraestructura necesarias" para dicha regulación, "acorde con los instrumentos internacionales" y con un "irrestricto respeto a los derechos humanos", incluyendo el de consulta previa, sobre el cual existen disposiciones en la Ley de Bioseguridad de Organismos Genéticamente Modificados.

En este sentido, la presentación de la secretaria ejecutiva de la Cibiogem consistía en representar al Estado mexicano y cómo éste cumple con la protección de los derechos humanos. "El Estado mexicano -afirmó-, por conducto particularmente de la Cibiogem y la CDI, se encuentra atendiendo tanto las resoluciones de la Suprema Corte como las recomendaciones de la CNDH" a través de la implementación del proceso de consulta indígena. Después de indicar que estaban dando una "oportuna atención de la sentencia" de la Suprema Corte, leyó la serie de actividades realizadas en el marco del proceso de consulta: la emisión de las convocatorias públicas, el número de sesiones, la elaboración del "programa de trabajo" que se hizo "conforme a la legislación nacional y el Convenio 169"; y destacó el caso de dos comunidades en las que los participantes se pronunciaron a favor de la siembra de soya (pero no mencionó que la mayoría está en contra).

A diferencia del comportamiento usual de los funcionarios estatales en este tipo de eventos, los integrantes de la delegación del Estado no intentaron desacreditar a los peticionarios (véase Price, 2011). Tanto en los conflictos por la soya gm como por los parques de energía renovable en la península de Yucatán, las autoridades suelen desestimar a los defensores de derechos humanos calificándolos de "oportunistas" e incluso "mercenarios políticos", que "viven del conflicto" consiguiendo recursos de fundaciones. En contraste, en sus intervenciones en la audiencia, los representantes del Estado se enfocaron en señalar el cumplimiento de la ley y del derecho internacional, aunque también, como la secretaria ejecutiva de la Cibiogem, ofrecieron versiones distintas de los temas expuestos por los peticionarios; por ejemplo, la secretaria mencionó que el glifosato está en uso desde la década de los setenta 
y que existe un potencial mínimo de contaminación de aguas subterráneas; además citó monitoreos de la Comisión Nacional del Agua que indican que ninguna medida de presencia de plaguicidas rebasa lo permitido por las normas.

Por su parte, el representante de la Secretaría de Energía (Sener) planteó el procedimiento de la subasta de largo plazo de energía eléctrica en la que se adjudicó el parque fotovoltaico Ticul A y Ticul B y refirió a los artículos 1 y 2 de la Constitución federal (relativos a derechos humanos y derechos de los pueblos indígenas, respectivamente), a la normatividad de la reforma energética y sus leyes secundarias. También, afirmó que "la empresa tiene la obligación de respetar los derechos humanos de las comunidades que se encuentran dentro del área de influencia del proyecto, y es obligación del Estado garantizar que así sea”. Reconoció que "efectivamente existen comunidades indígenas que deberán ser consultadas bajo los estándares internacionales que emanan del Convenio 169 de la orT y de la jurisprudencia del Sistema Interamericano de Derechos Humanos" y que la Sener llevaría a cabo las consultas, "en cumplimiento del marco normativo emanado de la reforma energética de 2013 y 2014".

Cabe destacar que, en sus encuentros con funcionarios de la Cibiogem y la Sener, los mayas que participan en los procesos de consulta (que se enfrentan al parque fotovoltaico) y las organizaciones que los acompañan en su defensa, han cuestionado a dichos funcionarios por considerar que están al servicio de empresas como Monsanto y Vega Solar. En su intervención en la audiencia, los funcionarios de la Cibiogem y la Sener, lejos de responder directamente a las acusaciones, realizaron actos "ritualistas": expusieron las medidas legales e institucionales que el Estado ha llevado a cabo para proteger derechos humanos. Mientras que las víctimas y sus defensores apelan a hechos, sean vivencias directas o indicadores y estudios, los agentes del Estado muestran las acciones legales y procedimientos que han ejecutado; presentan al Estado como algo meramente institucional, legal, ajeno a los intereses económicos denunciados por las víctimas y sus defensores.

Por último, en su intervención, el comisionado que presidió la sesión concluyó, con una posición conciliadora, que lo que evidenció la audiencia es "un requerimiento de diálogo [...] lo que hace falta es diálogo [...] [éste es] la mejor forma de justicia" y que la Comisión está "arbitrando" ese diálogo. Así, pidió al Estado "atender ese clamor de diálogo".

¿Cuáles han sido los efectos de esta audiencia? Aún es pronto para analizarlos con detenimiento, sin embargo, entre sus efectos directos, la Sener inició el proceso de consulta sobre el parque fotovoltaico Ticul, y el ejidatario de San José Tipceh que asistió a la audiencia me ha comentado, con orgullo, que la consulta se ha realizado gracias a este "viaje a Panamá". Por su parte, los efectos en el proceso de consulta sobre la soya en Campeche son más complejos de ponderar, pero la misión de observación que documenta el caso registró una posición de endurecimiento por parte de la Cibiogem posterior a la audiencia: después de más de un año de consulta, exigió a los participantes presentar actas que acrediten su representatividad ante sus comunidades. Y, finalmente, desde la perspectiva de los peticionarios, la audiencia fue un parteaguas para la visibilización de los problemas de los derechos indígenas en la península de Yucatán.

\section{Conclusión}

En la "era secular" (Taylor, 2014), la idea de derechos humanos se ha convertido en algo "sagrado": la dignidad inherente a los individuos no debe ser tocada, violada, profanada; debe ser respetada, protegida, cuidada. En este artículo he argumentado que dicha dignidad intrínseca, lejos de ser una verdad evidente, debe ser activamente producida, performada: declarada en textos, promovida en talleres de sensibilización o concientización, formulada en acciones legales, dramatizada en audiencias, entre otros campos y arenas políticas. La dimensión performativa de la defensa de los derechos humanos no sólo consiste en representar los ideales de derechos reconocidos en textos, sino también en activarlos, ponerlos en escena, hacerlos existir social, cultural y políticamente.

A partir del análisis de una audiencia temática sobre los derechos humanos de los pueblos indígenas en Yucatán he destacado algunas de las manifestaciones de la dimensión performativa de la defensa de los derechos: la movilización de emociones que busca tocar la fibra sensible de las audiencias, pero además representar identidades (de la víctima y del perpetrador), construir y reconstruir narrativas. Adicionalmente, en el contexto de la profesionalización de las organizaciones de derechos humanos, la dimensión performativa de su defensa cobra nuevas expresiones: se debe representar el profesionalismo, basado en el conocimiento del derecho y en la presentación de datos confiables. Al final, esta dimensión contribuye a la producción del efecto Estado: construye al Estado como un perpetrador de violaciones de derechos. Pero también los actores estatales recurren a los discursos de derechos para legitimarlo, ya sea mediante la firma y ratificación de tratados internacionales o con 
pronunciamientos sobre cómo llevan a cabo medidas legales e institucionales para cumplir las normas de derechos humanos.

Por último, la movilización de la emoción de tristeza y la actuación profesional que informa sobre la contaminación del agua performan un sentimiento de "pérdida" (Calderón Rivera, 2012), de daños, privaciones y despojo de recursos -como abejas, selva, agua limpia- que ya ha sucedido pero, sobre todo, que puede devenir en una grave crisis de derechos humanos como las que se viven en otras regiones de México. En este sentido, las performances no únicamente actúan como re-presentaciones de hechos ya ocurridos, sino que también anuncian lo posible. Esta audiencia fue, entonces, el encuentro de diversas expresiones de la dimensión performativa de la defensa de los derechos humanos en las cuales se presenta el sufrimiento real y posible provocado por los proyectos de desarrollo en el país.

\section{Fuentes}

Abrams, PhiliP

1988 "Notes on the Difficulty of Studying the State", en Journal of Historical Sociology, vol. 1 , núm. 1, pp. 58-89.

AdCOCK, Fleur

2012 "The un Special Rapporteur on the Rights of Indigenous Peoples and New Zealand: A Study in Compliance Ritualism", en New Zealand Yearbook of International Law, vol. 10, pp. 97-120.

Allen, Lori

2013 The Rise and Fall of Human Rights. Cynicism and Politics in Occupied Palestine, Stanford University Press, Stanford, 258 pp.

Austin, John L.

1990 Cómo hacer cosas con palabras, Paidós, Barcelona, $215 \mathrm{pp}$.

Beristain Navarro, Horacio

2014 "Democracia participativa, el caso de la apicultura y la introducción de soya genéticamente modificada en Yucatán", tesis de maestría en Ciencias en la especialidad de Ecología Humana, Instituto Politécnico Nacional-Centro de Investigación y Estudios Avanzados-Unidad Mérida, Mérida.

ButLer, Judith

2001 El género en disputa. El feminismo y la subversión de la identidad, Paidós/Universidad $\mathrm{Na}$ cional Autónoma de México, México, 316 pp.

Calderón Rivera, Edith

2012 La afectividad en antropología. Una estructura ausente, Centro de Investigaciones y Estudios Superiores en Antropología Social/ Universidad Autónoma Metropolitana, México, $262 \mathrm{pp}$

Comaroff, Jean y John L. Comaroff

2009 Violencia y ley en la poscolonia: una reflexión sobre las complicidades Norte-Sur, Katz, Barcelona, $131 \mathrm{pp}$
Díaz CRUz, Rodrigo

2008 "La celebración de la contingencia y la forma. Sobre la antropología de la performance", en Nueva Antropología, vol. 21, núm. 69, pp. 3359

DíAz CRuz, Rodrigo

2014a "Cuerpos desgarrados, vidas precarias: violencia, ritualización, performance”, en Alteridades, año 24, núm. 48, pp. 71-83.

Díaz Cruz, Rodrigo

2014b Los lugares de lo político, los desplazamientos del símbolo. Poder y simbolismo en la obra de Victor W. Turner, Universidad Autónoma Metropolitana-Iztapalapa/Gedisa, México, $412 \mathrm{pp}$.

Goffman, ERving

1981 La presentación de la persona en la vida cotidiana, Amorrortu, Buenos Aires, 280 pp.

Gupta, AkHIL

1995 "Blurred Boundaries: The Discourse of Corruption, the Culture of Politics, and the Imagined State", en American Ethnologist, vol. 22 , núm. 2, pp. 375-402.

Hale, Charles R.

2002 "Does Multiculturalism Menace? Governance, Cultural Rights and the Politics of Identity in Guatemala", en Journal of Latin American Studies, vol. 34, núm. 3, pp. 485-524.

HathaWAy, OONA A

2002 "Do Human Rights Treaties Make a Difference?", en The Yale Law Journal, vol. 111, pp. 1935-2042.

Hunt, LYNN

2009 La invención de los derechos humanos, Tusquets, Barcelona, 288 pp.

Kennedy, David

2002 "The International Human Rights Movement: Part of the Problem?", en Harvard Human Rights Journal, vol. 15, pp. 101-126.

Kovic, Christine

2005 Mayan Voices for Human Rights. Displaced Catholics in Highland Chiapas, University of Texas Press, Austin, 238 pp.

Lovatón, David

2017 "Yucatán no es sólo Cancún", en Aportes $D P L F$, año 9, núm. 21, pp. 58-59.

Llanes Salazar, Rodrigo

2019 “No sólo los ejidatarios tienen derechos'. La emergencia de los derechos humanos del pueblo maya en Yucatán", en Península, vol. 14, núm. 1, pp. 107-129.

Llanes Salazar, Rodrigo

Y Gabriela Torres-Mazuera

2017 "Perdidos en la traducción: redes de (in)comunicación en la consulta a las comunidades mayas sobre la siembra de soya transgénica en México", en Indiana, año 34, núm. 2, pp. 183-207.

Merry, Sally

2006 Human Rigths \& Gender Violence. Translating International Law into Local Justice, The Chicago University Press, Chicago, 269 pp.

Merry, SALly

2011 "Measuring the World. Indicators, Human Rights, and Global Governance", en Current Anthropology, vol. 52, núm. S3, pp. S83-S95.

MitChell, Timothy

1990 "Society, Economy, and the State Effect", en George Steinmetz (ed.), State/Culture: State- 
Mutua, Makau

Formation after the Cultural Turn, Cornell University Press, Ithaca, pp. 76-97.

2001 "Savages, Victims, and Saviors: The Metaphor of Human Rights", en Harvard International Law Journal, vol. 42, núm. 1, pp. 201 245.

Nader, Laura y Ugo Mattei

2013 Saqueo. Cuando el Estado de Derecho es ilegal, Palestra, Lima, 420 pp.

Perreault, Tom

2015 "Performing Participation: Mining, Power, and the Limits of Public Consultation in Bolivia", en The Journal of Latin American and Caribbe-

Pitarch, Pedro, Shannon Speed an Anthropology, vol. 20, núm. 3, pp. 433-451.

y Xóchitl Leyva (EDs.)

2008 Human Rights in the Maya Region, Duke University Press, Durham, 377 pp.

PRICE, RICHARD

2011 Rainforest Warriors. Human Rights on Trial, University of Pennsylvania Press, Filadelfia, $276 \mathrm{pp}$.

Sierra, María Teresa, Aída Hernández

y RACHEL Sieder (EDS.)

2013 Justicias indígenas y Estado: violencias contemporáneas, Facultad Latinoamericana de Ciencias Sociales/Centro de Investigaciones y Estudios Superiores en Antropología Social, México, 426 pp.

Simmons, Beth A.

2009 Mobilizing for Human Rights. International Law in Domestic Politics, Cambridge University Press, Nueva York, 451 pp.

Speed, Shannon

2008 Rights in Rebellion. Indigenous Struggle \& Human Rights in Chiapas, Stanford University Press, Stanford, 244 pp.

TATE, WiNIFRED

2007 Counting the Dead. The Culture and Politics of Human Rights Activism in Colombia, Universi-

TAYLOR, CHARLES ty of California Press, Berkeley, 379 pp.

2014 La era secular, Gedisa, Barcelona, 480 pp. TAYLOR, DiAnA

1997 Disappearing Acts. Spectacles of Gender and Nationalism in Argentina's "Dirty War", Duke

WACQUANT, LÖIC University Press, Durham, 309 pp.

2010 Castigaralospobres. Elgobiernoneoliberaldela inseguridad social, Gedisa, Barcelona, 446 pp.

WILSON, RICHARD

1997 "Human Rights, Culture and Context: An Introduction", en Richard Wilson (ed.), Human Rights, Culture \& Context. Anthropological Perspectives, Pluto Press, Londres, pp. 1-27. 